\title{
$\alpha$-Diimine Synthesis via Titanium-Mediated Multicomponent Diimination of Alkynes with C-Nitrosos
}

\author{
Connor W. Frye, Dominic T. Egger, Errikos Kounalis, Adam J. Pearce, Yukun Cheng, and lan A. Tonks* \\ Department of Chemistry, University of Minnesota-Twin Cities, 207 Pleasant Street SE, Minneapolis, Minnesota 55455, \\ United States
}

\begin{abstract}
Diimines are commonly used as supporting ligands for a variety of transition metal-catalyzed processes, most notably in $\alpha$-olefin polymerization. They are also precursors to valuable synthetic targets, such as chiral 1,2-diamines. Their synthesis is usually performed through acid-catalyzed condensation of amines with $\alpha$-diketones. Despite the simplicity of this approach, accessing unsymmetrical $\alpha$-diimines is challenging. Herein, we report the Ti-mediated intermolecular diimination of alkynes to afford a variety of symmetrical and unsymmetrical $\alpha$-diimines through the reaction of diazatitanacyclohexadiene intermediates with $C$-nitrosos. These diazatitanacycles can be readily accessed in situ via the multicomponent coupling of Ti=NR imidos with alkynes and nitriles. The formation of $\alpha$-diimines is achieved through formal [4+2]-cycloaddition of the $C$-nitroso to the Ti and $\gamma$ carbon of the diazatitanacyclohexadiene followed by two subsequent cycloreversion steps to eliminate nitrile and afford the $\alpha$ diimine and a Ti oxo.
\end{abstract}

\section{Introduction}

$\alpha$-Diimines (1,4-diaza-1,3-dienes) are widely used as ligands for organometallic complexes, ${ }^{1-2}$ perhaps most notably in Brookhart-type catalysts for $\alpha$-olefin polymerization..$^{3-5}$ The $\alpha$-diimine ligand scaffold has proven to be remarkably versatile due to its facile stereoelectronic tunability. ${ }^{6-9}$ For example, modifications to the backbone and $\mathrm{N}$-aryl substituents of $\alpha$-diimines can exert control over the molecular weight and microstructure of $\alpha$-olefin polymers by attenuation of chain walking processes. ${ }^{1,10} \alpha$-Diimine ligands are also often redox non-innocent, which allows for richer and more complex redox processes. ${ }^{11-14} \alpha$-Diimines are also precursors to valuable chiral 1,2-diamines through asymmetric hydrogenation, ${ }^{15-16}$ or to $\mathrm{N}$-heterocyclic carbene (NHC) ligands through cyclization with paraformaldehyde and subsequent deprotonation. ${ }^{17-20}$

Typically, $\alpha$-diimines are synthesized through condensation of $\alpha$-diketones and amines. Despite the apparent simplicity of this approach, accessing unsymmetrical $\alpha$-diimines through stepwise condensations is synthetically challenging due to poor chemoselectivity. ${ }^{21}$ Furthermore, since imine formation is reversible, attempts at sequential selective condensations can result in complex mixtures (for example, see Figure 1A, Figures S93-S96). Imines are also notoriously difficult to isolate because they are prone to hydrolysis, making methods that generate product mixtures impractical. Highlighting this problem, although amine condensation with glyoxal to afford $\alpha$ diimines is a common route to symmetric NHCs there remain no examples of unsymmetric NHCs synthesized via condensation with glyoxal. ${ }^{22}$

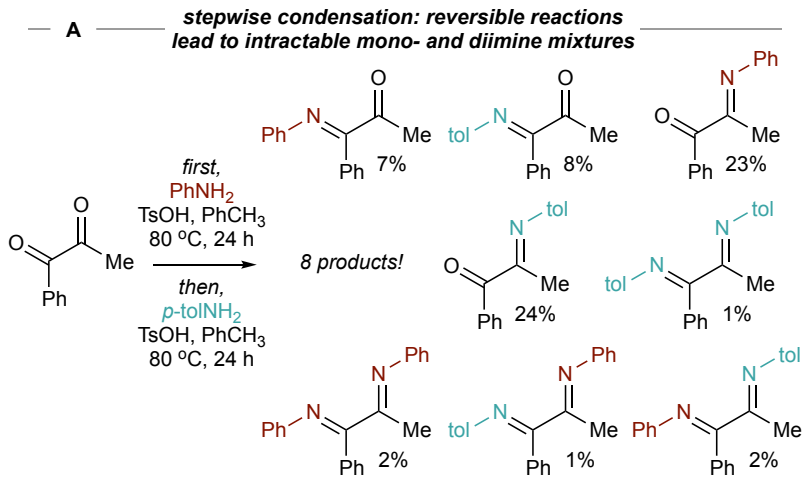

- B - successful stepwise condensation with bulky arylamines

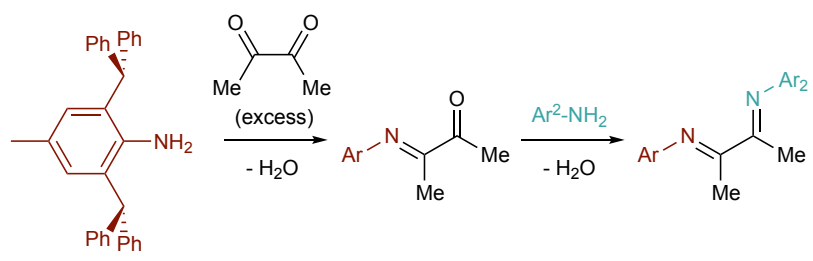

Figure 1. Challenges and current strategies for unsymmetric $\alpha$ diimine synthesis.

There are comparatively few examples of unsymmetrical $\alpha$-diimines, and these are mostly limited to $\mathrm{N}$-aryl substituent modifications involving very sterically encumbered groups ${ }^{3,9}$, ${ }^{23}$ rather than backbone substitution (Figure 1B). ${ }^{11,} 24-25$ Selective trapping of unsymmetrical diimines via cyclization has also recently been reported. ${ }^{26}$ Given this methodology gap, developing a route to these unsymmetrical $\alpha$-diimines from simple feedstocks would provide a useful tool for the development of more diverse ligand scaffolds and pharmaceutically relevant building blocks..$^{3,15-16}$ 
Our group has reported several examples of Ti-catalyzed oxidative functionalizations of alkynes for the synthesis of multisubstituted $\mathrm{N}$-heterocycles that overcome limitations of classical condensation reactions. ${ }^{27-30}$ We envisioned that a complementary synthetic route to unsymmetrical $\alpha$ diimines could be achieved through Ti-mediated oxidative diimination of alkynes. Examples of alkyne diamination or diimination are scarce ${ }^{31-34}$ despite many reports of alkene diamination. ${ }^{35-40}$ To the best of our knowledge, there is only a single example of a multicomponent intermolecular alkyne diamination $^{41}$ and no examples of alkyne diimination. Nevertheless, there are several elegant examples of alkyne difunctionalizations ${ }^{42}$ using $\mathrm{Ti}$ including alkyne carboamination $^{43-45}$ and iminoamination ${ }^{46}$ that provide motivation for further exploring Ti-catalyzed or -mediated diamination/diimination.

Previously, we reported that diazatitanacyclohexadienes (prepared from the multicomponent coupling of $\mathrm{Ti}$ imidos, alkynes, and nitriles) could undergo oxidation-induced N-N coupling to yield pyrazoles (Figure 2, top). ${ }^{30}$ In the interest of further expanding the utility of this unique intermediate, we have begun examining its reactivity with various group transfer reagents. Herein, we report the intermolecular diimination of alkynes by $\mathrm{Ti}$ imidos and $C$-nitrosos to afford unsymmetrical $\alpha$-diimines (Figure 2, bottom). This diimination reaction proceeds through a cascading sequence of formal cycloaddition and retrocycloaddition reactions from this key diazatitanacyclohexadiene intermediate. This approach is a useful strategy for synthesizing unsymmetrical $\alpha$-diimines, which are challenging to access through traditional condensation reactions.

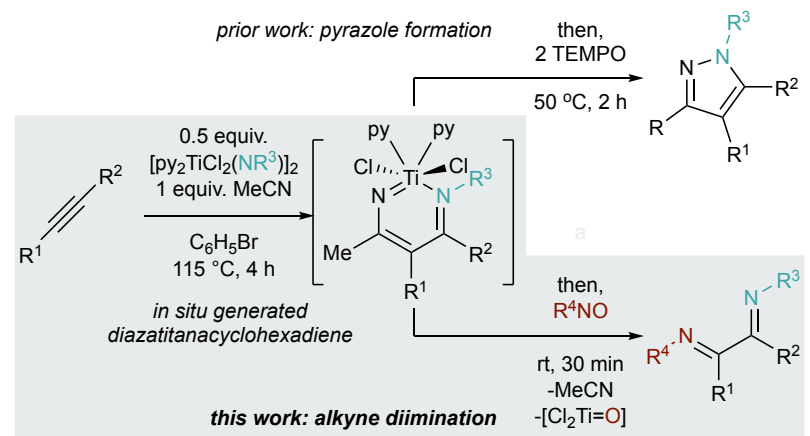

Figure 2. In situ generated diazatitanacycloehexadiene intermediates in synthesis. Top: previous work on oxidative N-N coupling to pyrazoles (top), and intermolecular diimination of alkynes (this work, bottom).

Addition of $\boldsymbol{C}$-nitrosos to Diazatitanacyclohexadienes. Addition of PhNO (2a) to diazatitanacycle 1 resulted in rapid, near-quantitative formation of $\alpha$-diimine $3 a\left(81 \%\right.$ by ${ }^{1} \mathrm{H}$ NMR) with the concomitant formation of $p$-tolunitrile (Figure $3)$. It is proposed that this occurs through [4+2]-cycloaddition of PhNO to the $\mathrm{Ti}$ and $\gamma$-carbon of the ligand backbone, followed by [4+2]-retrocycloaddition to eliminate $p$ tolunitrile, and a second cycloreversion to afford $\mathbf{3 a}$ and a $\mathrm{Ti}=\mathrm{O}$ species (vide infra).
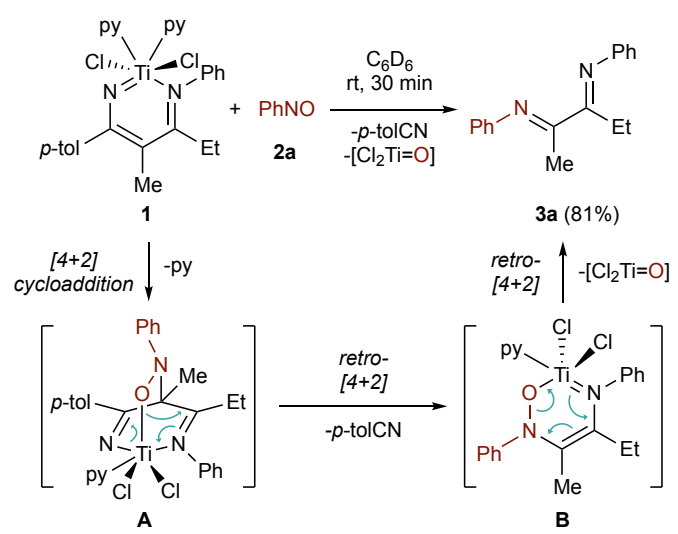

Figure 3. Reaction of a $C$-nitroso with $\mathbf{1}$ yields an $\alpha$-diimine 3a via a sequence of cycloaddition/retrocycloaddition steps.

Table 1. Substrate scope of the addition of $C$-nitrosos to 1 .
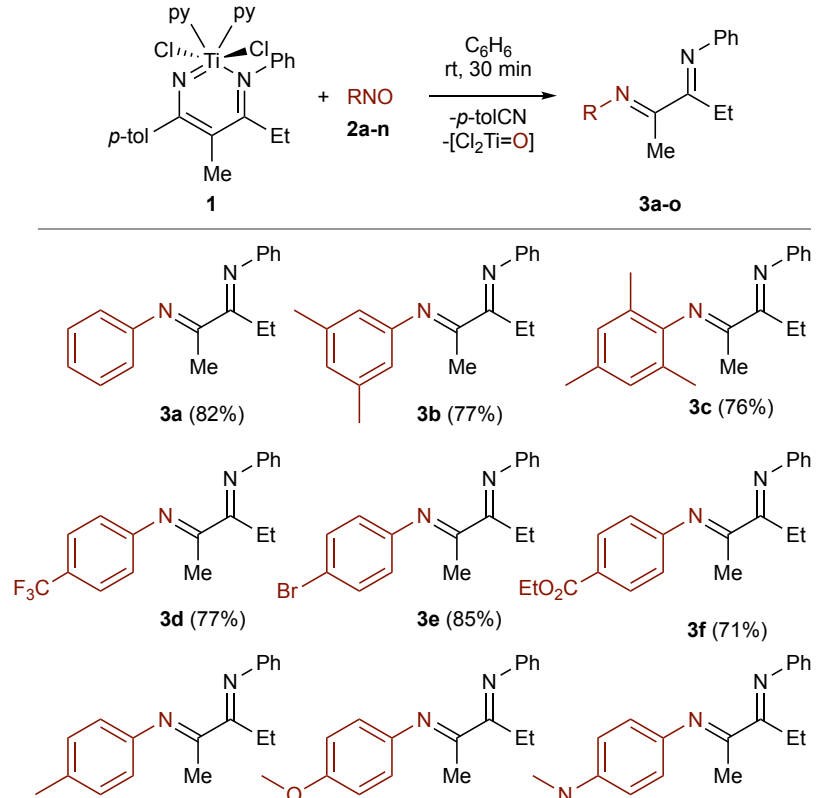

$3 g(84 \%)$

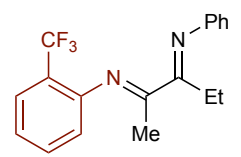

$3 \mathrm{~h}(82 \%)$ $3 \mathbf{i}(49 \%)^{\mathrm{c}}$

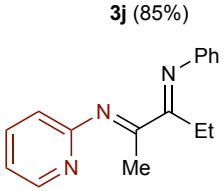

$3 \mathrm{~m}(20 \%)^{\mathrm{c}}$

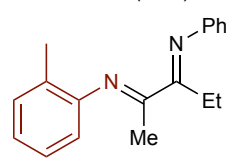

3k $(74 \%)$<smiles>CCC(=Nc1ccccc1)C(C)=Nc1ccccc1OC</smiles>

$3 \mathbf{l}(74 \%)^{b}$

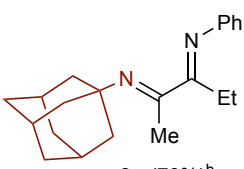

3o $(70 \%)^{b}$
aConditions: 1 ( $0.2 \mathrm{mmol})$, 2a-o ( $0.2 \mathrm{mmol}, 1$ equiv.), $3 \mathrm{~mL} \mathrm{C}_{6} \mathrm{H}_{6}$. Isolated yields. ${ }^{b}$ Mixture of imine/enamine tautomers; see $\mathrm{SI}$ for ratios. ${ }^{\mathrm{C}}$ Not isolated, ${ }^{1} \mathrm{H}$ NMR yield vs. 1,3,5-trimethoxybenzene internal standard.

The scope of the $C$-nitroso reactants examined is shown in Table 1. Conveniently, nitrosoarenes can be readily prepared from the corresponding aniline via Oxone ${ }^{\circledR}$ oxidation. ${ }^{47}$ In most cases, the $\alpha$-diimine products were obtained in excellent isolated yields ( $70 \%$ to $85 \%)$. Use of sterically demanding nitrosos $\mathbf{2} \mathbf{b}$ and $\mathbf{2 c}$ resulted in good yields of $\mathbf{3 b}$ and $3 c(77 \%$ and $76 \%)$, which are commonly used as bulky $\alpha$ diimine substituents. ${ }^{3}$ This method tolerates both electron- 
poor (3d-3f) and electron-rich (3g-3i) para-substituted (3d3i) nitrosoarenes, as well as ortho-substituted (3j-3l) nitrosoarenes ( $\mathbf{3 l}$ is formed in a 6:1 ratio with its enamine tautomer). The reaction also proceeds cleanly with aliphatic nitrosos: 2-methyl-2-nitrosopropane $\mathbf{2 n}$ gives a mixture of tert-butyl substituted $\alpha$-diimine $3 \mathbf{n}$ and its enamine tautomer in a 3.75:1 ratio (71\%). Similarly, 1-nitrosoadamantane 20 afforded $\alpha$-diimine 30 and its enamine tautomer in a 3.13:1 ratio $(70 \%)$. While the yield of the reaction was mostly consistent irrespective of nitrosoarene substituent, there were a couple of exceptions. For the reaction with electronrich $\mathbf{2} \mathbf{i}$, the formation of $\alpha$-diimine $\mathbf{3 i}$ ( $49 \%$ yield by ${ }^{1} \mathrm{H}$ NMR) was accompanied by the formation of unidentified side products that precluded isolation. Also, the reaction with 2nitrosopyridine $2 \mathrm{~m}$ yielded only a small amount of $3 \mathrm{~m}$ by ${ }^{1} \mathrm{H}$ NMR $(20 \%)$ relative to the amount of $p$-tolunitrile byproduct (85\%).
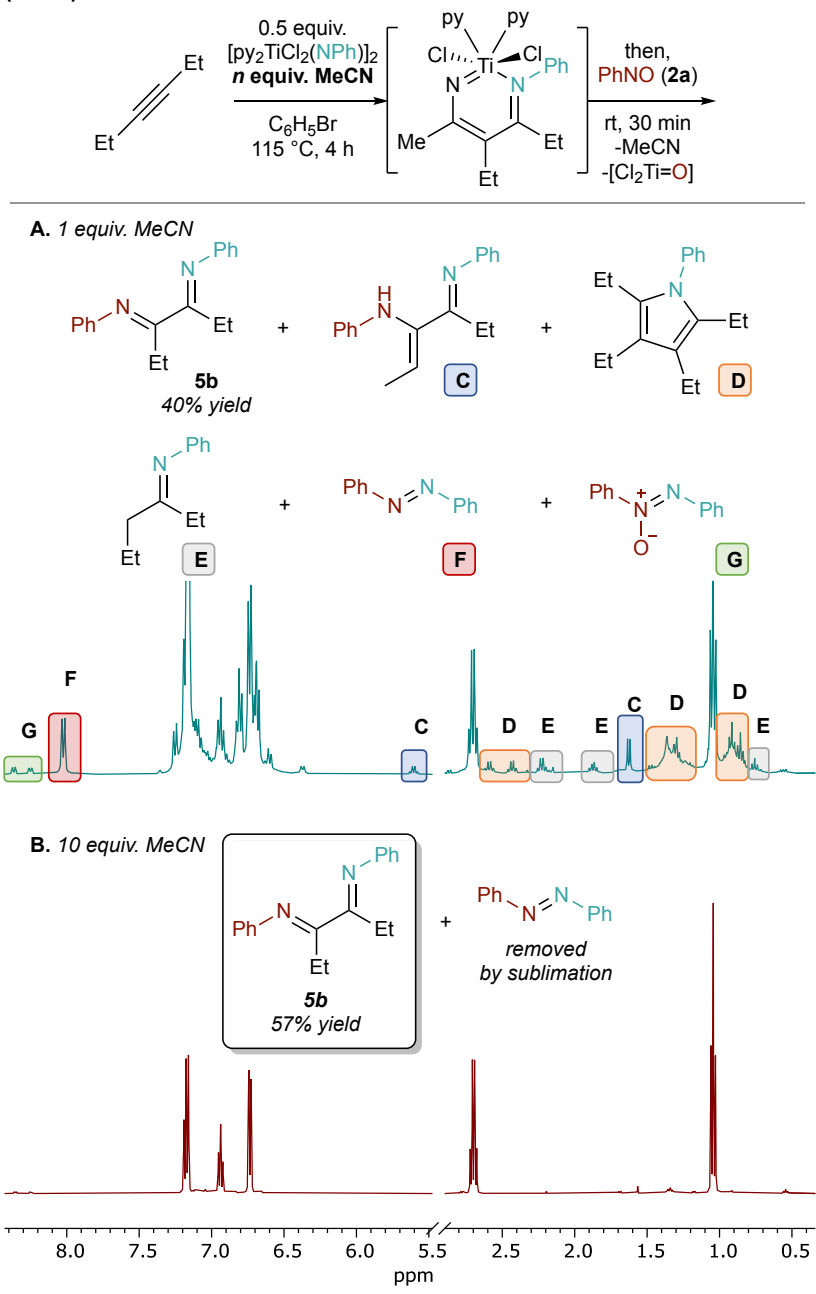

Figure 4. Comparison of synthesis of $\mathbf{5 b}$ using (A) 1 equiv. or (B) 10 equiv. MeCN.

In situ multicomponent diimine synthesis. Diazatitanacycles such as $\mathbf{1}$ can be synthesized via the multicomponent coupling of Ti imidos, alkynes, and nitriles. ${ }^{30}$ With this strategy, one-pot alkyne diiminations were carried out (Figure 4, Table 2). In an initial experiment, reactions with 1 equiv. MeCN led to moderate yields of $5 \mathbf{b}(40 \%)$ from reaction of $\mathbf{4 b}$ and $\mathrm{PhNO}$ (Figure $4 \mathrm{~A}$ ). However, several species from competing side reactions also formed that were difficult to separate from the desired product given the instability of diimines towards hydrolysis: pyrrole (D, 5\%) from insertion of a second equivalent of alkyne; ${ }^{27}$ imine from the hydroamination of 3-hexyne (E, 6\%); and azobenzene (F, 12\%) from direct metathesis of PhNO with leftover Ti imido. ${ }^{48-49}$ Using excess MeCN (10 equiv.) suppressed these competing side reactions (Figure $4 \mathrm{~B}$ ) and leads to cleaner formation of the product, with azobenzene as the predominant side-product. Conveniently, basic aqueous extraction can remove the Ti byproducts, and azobenzene can be easily removed by sublimation-avoiding the need to perform column chromatography on the sensitive products.

Based on this result, the scope of one-pot oxidative alkyne diimination with $\left[\mathrm{py}_{2} \mathrm{TiCl}_{2} \mathrm{NPh}\right]_{2}$ and $\mathrm{PhNO}$ was examined (Table 2, 5a-5p). Here, the $\alpha$-diimine yields are ultimately determined by the yield of in situ formed diazatitanacycle 1a$1 p$, as the subsequent oxidations are near-quantitative. Symmetrical internal alkynes with both alkyl and aryl substituents formed the respective $\alpha$-diimines (5a-5d) in good isolated yields ( $51 \%$ to $63 \%$ ).

Table 2. Substrate scope of one-pot in situ diimine synthesis from alkynes, imidos, and $C$-nitrosos. ${ }^{a}$
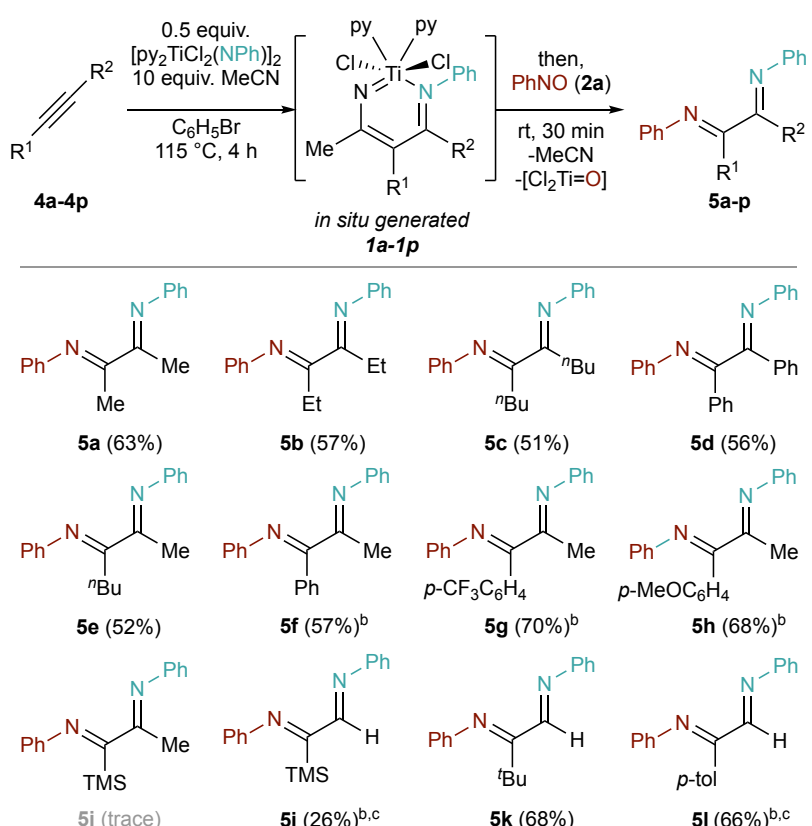<smiles>C=CCCC(=Nc1ccccc1)C(Br)=Nc1ccccc1</smiles>

$5 \mathrm{~m}(50 \%)$<smiles>C=CCCC(=Nc1ccccc1)C(=Nc1ccccc1)c1ccccc1</smiles><smiles>BrC(/C=N/c1ccccc1)=N\c1ccccc1</smiles><smiles>OC(C=Nc1ccccc1)=Nc1ccccc1</smiles><smiles>C=C(C)C(=Nc1ccccc1)C(CC)=Nc1ccccc1</smiles>

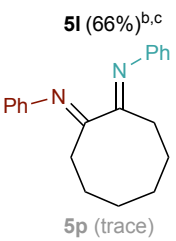

aconditions: $0.2 \mathrm{mmol}\left(0.5\right.$ equiv.) $\left[\mathrm{py}_{2} \mathrm{TiCl}_{2}(\mathrm{NPh})\right]_{2}, 0.4 \mathrm{mmol}$ ( 1 equiv.) alkyne, $4.0 \mathrm{mmol}$ (10 equiv.) $\mathrm{MeCN}, 4 \mathrm{~mL} \mathrm{PhBr}, 115{ }^{\circ} \mathrm{C}, 4 \mathrm{~h}$; then, 0.4 mmol (1 equiv.) PhNO, rt, $0.5 \mathrm{~h}$. Isolated yields. ${ }^{b}$ Mixture of stereoisomers. 'Yield corrected for minor pyrrole impurities. ${ }^{\mathrm{d}} \mathrm{GC}-\mathrm{FID}$ yield (vs. 1,3,5-trimethoxybenzene standard).

Unsymmetrical internal alkyne $4 \mathbf{e}$ resulted in the formation of a single $\alpha$-diimine isomer (5e) in a $52 \%$ yield. In contrast, $\alpha$-diimines $\mathbf{5 f - 5 h}$ give complex ${ }^{1} \mathrm{H}$ and ${ }^{13} \mathrm{C}$ NMR spectra, presumably due to formation of multiple imine 
stereoisomers. Analysis of $\mathbf{5 f}$ by NOESY (Figures S51-2) showed that chemical exchange occurs between each of these isomers by the presence of EXSY cross-peaks. Additionally, GC-MS revealed only one peak corresponding to the mass of $\mathbf{5 f}$ (Figure S53). Imines are well-known to undergo rapid equilibrium between $E / Z$ isomers through inversion (also called the lateral shift mechanism) in nonpolar solvents. ${ }^{50}$ Confirmation that the complex spectra of $\mathbf{5 f - 5 h}$ were a result of stereoisomer equilibration was obtained through further reaction of the isomer mixtures. For example, reaction of the $\mathbf{5 f}$ isomeric mixture with $\mathrm{ZnCl}_{2}$ resulted in $93 \%$ yield of $\alpha$-diimine adduct $\mathbf{6 f}$ (Figure 5 ). $\alpha$-The identities of diimines $\mathbf{5 g}$ and $\mathbf{5 h}$ were similarly confirmed via $\mathrm{ZnCl}_{2}$ coordination (see $\mathrm{SI}$ ).

Terminal alkynes $\mathbf{4 j - 4 I}$ were also examined. Trapping Ti=NR + terminal alkyne [2+2] cycloadducts with nitriles to form the diazatitanacyclohexadiene intermediate is challenging: terminal alkynes typically react faster to form pyrrole or alkyne trimerization products. ${ }^{51}$ Nevertheless, $\mathbf{5 k}$ was obtained cleanly in a $68 \%$ yield, while $5 \mathbf{j}$ and $\mathbf{5 l}$ were obtained as a mixture of stereoisomers with small pyrrole impurities ( $2.4 \%$ and $12 \%$ pyrrole, respectively).

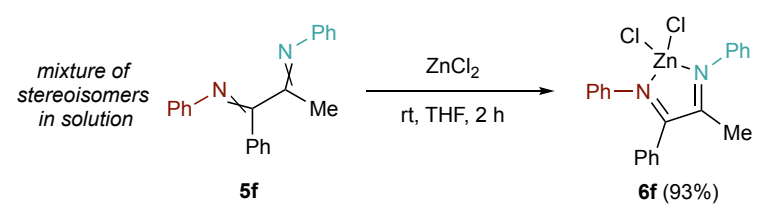

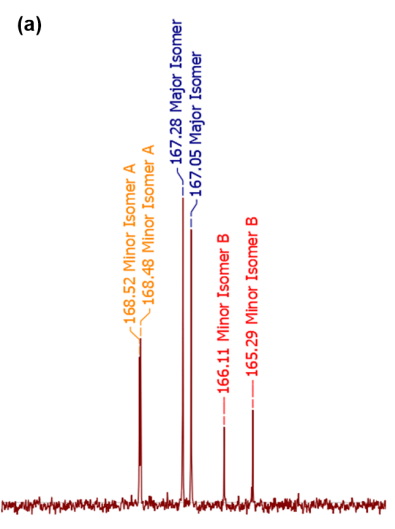

172171170169168167166165164163162 $\mathrm{ppm}$

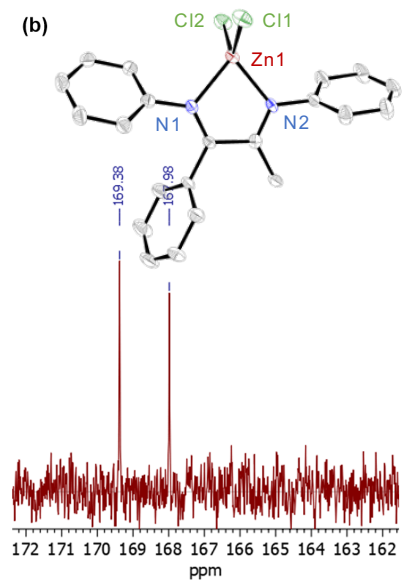

$\mathrm{ppm}$
Figure 5. Top: reaction of stereoisomeric mixture $\mathbf{5 f}$ with $\mathrm{ZnCl}_{2}$ results in convergence to $6 \mathrm{f}$. Bottom: ${ }^{13} \mathrm{C}$ NMR imine region of (a) $\mathbf{5 f}\left(\mathrm{C}_{6} \mathrm{D}_{6}\right)$ and (b) $\mathbf{6 f}\left(\mathrm{CDCl}_{3}\right)$. Inset: crystal structure of $\mathbf{6 f}$ showing half of asymmetric unit with residual solvent and protons omitted for clarity.

1,5-enyne $\mathbf{4 m}$ allows for clean formation of $\mathbf{5 m}$ (50\%), while 1,6-enyne $4 \mathrm{n}$ results in formation of $5 \mathrm{n}(10 \%)$ as a mixture with competing carboamination ${ }^{45}$ products $(6 \%)$. Here, the shorter linker of $\mathbf{4 m}$ compared to $\mathbf{4 n}$ prevents the intramolecular alkene insertion that would lead to carboamination. Conjugated enyne $\mathbf{4 0}$ yielded only trace $\mathbf{5 0}$, while cyclooctyne $4 p$ predominantly formed alkyne trimer and pyrrole, with only a trace amount of $5 p$.

$\mathbf{5 d}$ was also synthesized via a telescoped in situ route from $\mathrm{TiCl}_{4}(\mathrm{THF})_{2}$, azobenzene, and $\mathrm{Zn}^{0}$ powder with only a moderate decrease in yield (Figure 6). We have previously shown that this strategy is a benchtop-compatible approach to other Ti oxidative amination reactions. ${ }^{52}$

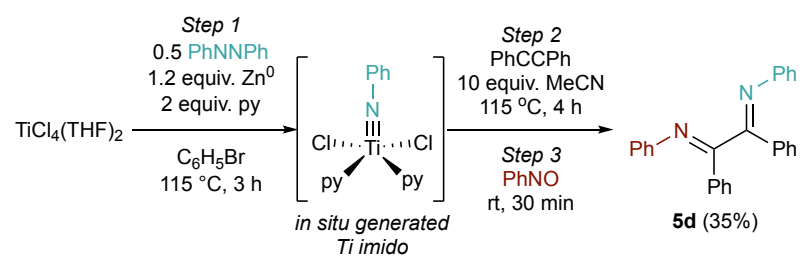

Figure 6. Telescoped one-pot synthesis of $\mathbf{5} \mathbf{d}$ from $\mathrm{TiCl}_{4}(\mathrm{THF})_{2}$.

Given that diazatitanacyclohexadiene intermediate formation is regioselective, ${ }^{30,53-55}$ this method could be used to prepare regioisomeric $\alpha$-diimines through different combinations of alkynes, imidos, and nitrosos (Figure 7). For example, reaction of $\mathbf{4 k}$ with $\left[\mathrm{py}_{2} \mathrm{TiCl}_{2}(\mathrm{~Np} \text {-tol })\right]_{2}$ imido gives $\mathbf{5 q}(41 \%)$, while its regioisomer $\mathbf{5} \mathbf{r}$ can be synthesized by using $2 \mathrm{~g}$ and $\left[\mathrm{py}_{2} \mathrm{TiCl}_{2}(\mathrm{NPh})\right]_{2}(44 \%)$. Another regioisomer $5 \mathrm{~s}$ can be prepared from $\left[\mathrm{py}_{2} \mathrm{TiCl}_{2}\left(\mathrm{~N}^{t} \mathrm{Bu}\right)\right]_{2}$ with a $50 \%$ yield of diimine stereoisomers, albeit with a small pyrrole impurity ( $4 \%$ yield).

Together, these reaction scopes demonstrate that a wide range of both symmetric and unsymmetric $\alpha$-diimines can be accessed directly through a one-pot multicomponent reaction with a variety of $\mathrm{Ti}$ imidos, alkynes, and $C$-nitrosos.

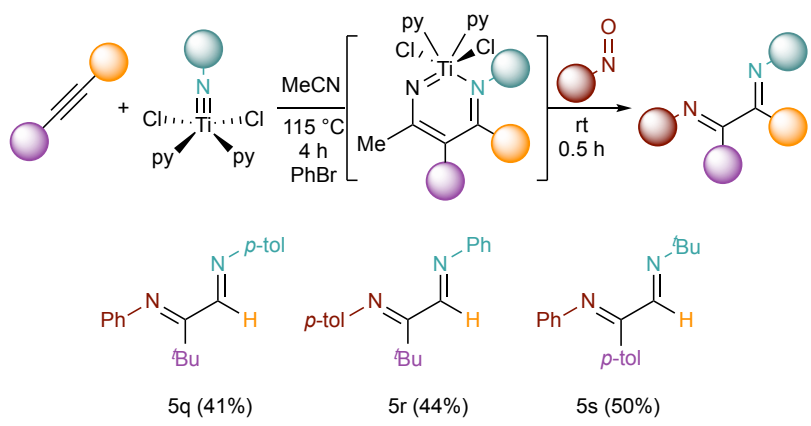

Figure 7. Modular strategy for the synthesis of $\alpha$-diimine regioisomers.

Proposed mechanism for intermolecular diimination. A plausible mechanism and accompanying DFT calculations for the formation of $\mathbf{5 a}$ from $\mathbf{1 a}$ (IM1) and PhNO (2a) is shown in Figure 8. The in situ formation of IM1 from Ti imidos, alkynes, and nitriles through alkyne/imido [2+2]-cycloaddition and nitrile insertion has been previously established. ${ }^{30,56-58}$ The formal [4+2] cycloaddition of PhNO to IM1 occurs in a stepwise fashion. First, O-coordination of $\mathrm{PhNO}$ to $\mathrm{Ti}$ yields IM3. From IM3, the nucleophilic, electron-rich $\gamma$-carbon in the metallacycle backbone ${ }^{59}$ attacks the electrophilic $\mathrm{N}$ of coordinated PhNO, generating bicyclic IM4. This process can be further visualized using IBO analysis (Figure 8a): coordination of $\mathrm{PhNO}$ results in a puckering of the $\mathrm{\gamma}$-C orbital toward the $\mathrm{N}$ of coordinated PhNO. Subsequently the new $\mathrm{N}$ $\mathrm{C} \sigma$-bond is formed in IM4, with simultaneous rearrangement of the Ti-N and $\mathrm{N}-\mathrm{O} \pi$-bonds to a new N-C $\pi$-bond and $\mathrm{O}$ lone pair, respectively. The tendency of $C$-nitrosos to undergo 
(b) retro-[4+2] cycloaddition IBO analysis:

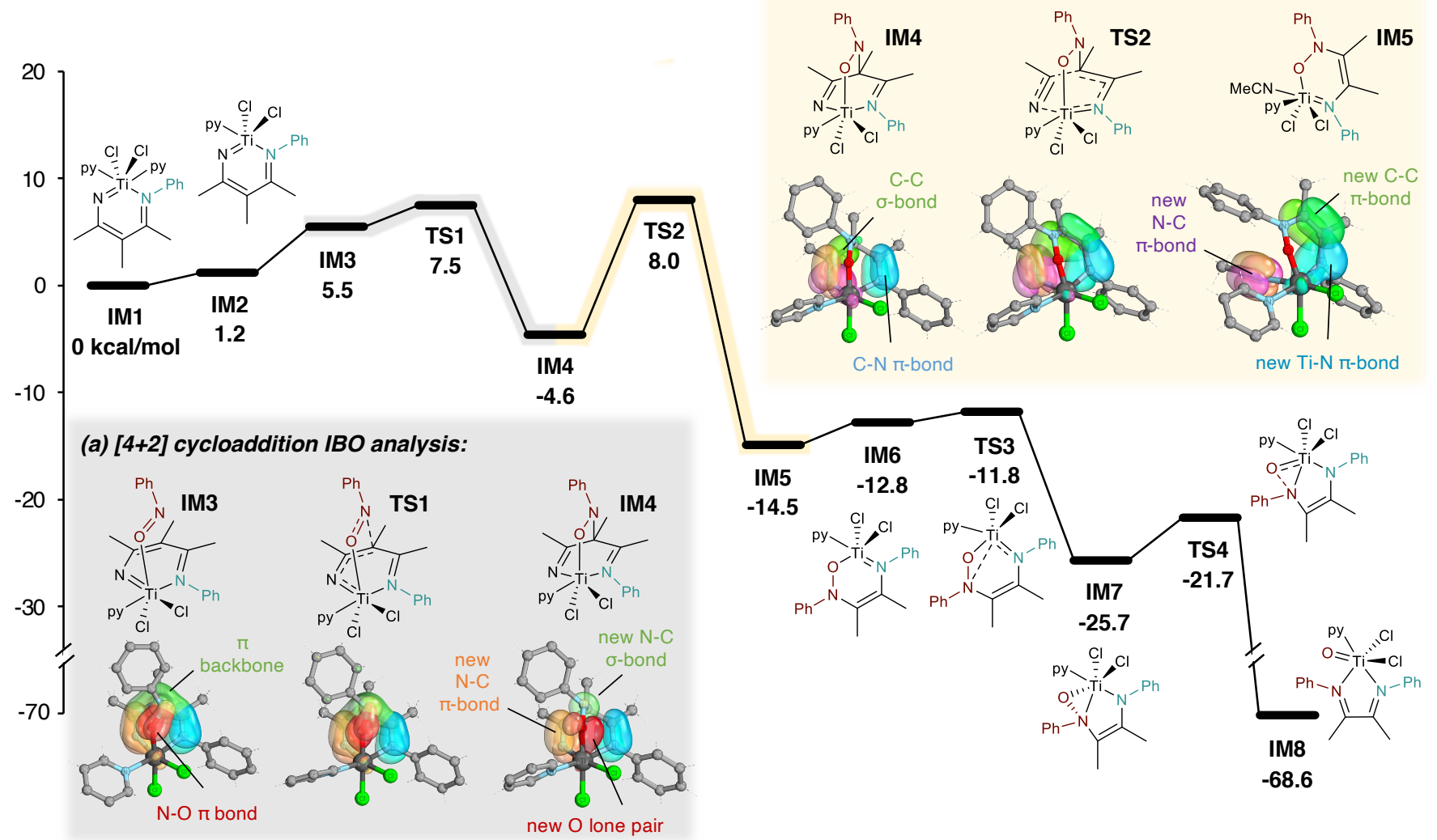

Figure 8. Computed pathway for diimine formation (M06/6-311G(d,p)/SMD, $25{ }^{\circ} \mathrm{C}, \mathrm{C}_{6} \mathrm{H}_{5} \mathrm{Br}$ ). All free energies are referenced to IM1 $=0.0$ $\mathrm{kcal} / \mathrm{mol}$. (a) Intrinsic bond orbitals (IBOs) showing [4+2] cycloaddition between NO $\pi$-bond (red) orbital of coordinated PhNO and $\pi$ backbone (green orbital) of IM3. (b) IBOs showing rearrangement of IM4 to IM5 via retro-[4+2] cycloaddition.

Diels-Alder-type cycloaddition reactions is well known, ${ }^{60-61}$ but examples of this process with metallacycles are scarce. ${ }^{62-}$ 63 Titanium $\beta$-diketiminate complexes, which differ from diazatitanacyclohexadienes by a degree of unsaturation, have also been observed to undergo [4+2]-cycloaddition with ketenes. $^{64-65}$

IM4 then undergoes rate-determining $(12.6 \mathrm{kcal} / \mathrm{mol})$ retro-[4+2] cycloaddition to extrude nitrile, forming azaoxatitanacycle IM5. The retrocycloadditive nature of TS2 can also be visualized by IBO calculations (Figure $8 \mathrm{~b}$ ), which show the elimination of nitrile by the breaking of $\mathrm{C}-\mathrm{C}$ and $\mathrm{Ti}-$ $\mathrm{N} \sigma$-bonds in IM4 and the formation of three new N-C, C-C, and Ti-N $\pi$-bonds in IM5. Further IBO analysis is provided in Figure S98. A similar tandem [4+2]-cycloadditioncycloreversion process to eliminate nitriles has also been proposed in the synthesis of phosphinines. ${ }^{66}$ IM5 then undergoes a haptotropic shift following loss of the coordinated nitrile (IM6) generating $\eta^{2}-(\mathrm{N}, \mathrm{O})$-bound IM7. Finally, $\mathrm{N}-\mathrm{O}$ bond cleavage results in exothermic formation of a $\mathrm{Ti}=\mathrm{O}$ species with the bound $\alpha$-diimine product IM8. ${ }^{67}$ Cycloreversions of group IV heterometallacycles to yield $\mathrm{M}=\mathrm{X}$ $(\mathrm{M}=\mathrm{Ti}, \mathrm{Zr} ; \mathrm{X}=\mathrm{O}, \mathrm{N})$ are well-precedented. ${ }^{68-73}$

Ultimately, nitrile serves as a promoter in the in situ reactions-first forming the key diazatitanacycle intermediate, and then being eliminated prior to product formation. Alternatively, instead of undergoing a [4+2]cycloaddition, a nitroso could directly insert into the [2+2]
alkyne/Ti=NR cycloadduct, bypassing the need for nitrile. Indeed, $\mathrm{C}$-nitrosos undergo insertions with $\mathrm{Ti}$ and $\mathrm{Zr}$ metallacycles. ${ }^{74-75}$ However, a nitrile-free control reaction resulted in exclusive formation of azobenzene through metathesis of the Ti imido with PhNO (Figure 9), making this route unlikely. ${ }^{48-49}$

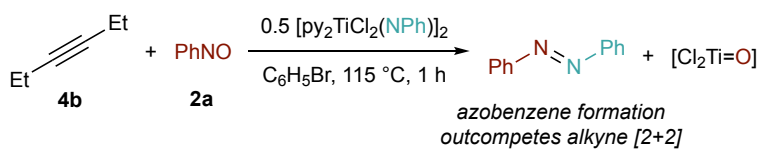

Figure 9. Direct reaction of nitrosos with $\mathrm{Ti}$ imidos and alkynes results in formation of azobenzene.

In summary, we have demonstrated a one-pot multicomponent synthesis of $\alpha$-diimines by the diimination of alkynes by $\mathrm{Ti}$ imidos and $C$-nitrosos. This reaction likely occurs by [4+2]-cycloaddition of a nitroso to the Ti and $\gamma$ carbon of a diazatitanacyclohexadiene intermediate, followed by two subsequent cycloreversion steps to eliminate nitrile and afford the $\alpha$-diimine and $\mathrm{Ti}=\mathrm{O}$. This is an attractive route to complex, unsymmetrical $\alpha$-diimines that are difficult to obtain through classical condensation reactions, providing new strategies for ligand synthesis, 3, 18, 20 and generally adding to the library of alkyne difunctionalization reactions. Efforts are ongoing to make 
this cycloaddition-retrocyclization strategy generalizable to other difunctionalizations.

\section{Supporting Information}

PDF file of full experimental and computational details.

\section{Corresponding Author}

*itonks@umn.edu

\section{Funding Sources}

Financial support was provided by the National Institutes of Health (R35GM119457), and the Alfred P. Sloan Foundation (I.A.T. is a 2017 Sloan Fellow). D.T.E. kindly acknowledges financial support by the ETH Zurich foundation (D.T.E. is a 2019 ESOP scholar). Y.C. acknowledges funding support from the Wayland E. Noland Fellowship (UMN). Instrumentation for the University of Minnesota Chemistry NMR facility was supported from a grant through the National Institutes of Health (S100D011952). X-ray diffraction experiments were performed with a diffractometer purchased through a grant from NSF/MRI (1229400) and the University of Minnesota.

\section{ACKNOWLEDGMENT}

Dr. Evan Beaumier, Dr. Robin Harkins, and Dr. Xuelan Wen are acknowledged for helpful discussions. The Minnesota Supercomputing Institute (MSI) at the University of Minnesota for provided resources that contributed to the results reported within this paper.

\section{REFERENCES}

(1) Johnson, L. K.; Killian, C. M.; Brookhart, M., New Pd(II)- and Ni(II)Based Catalysts for Polymerization of Ethylene and $\alpha$-Olefins. J. Am. Chem. Soc. 1995, 117(23), 6414-6415.

(2) Léonard, N. G.; Chirik, P. J., Air-Stable $\alpha$-Diimine Nickel Precatalysts for the Hydrogenation of Hindered, Unactivated Alkenes. ACS Catal. 2018, $8(1)$, 342-348.

(3) Wang, F.; Chen, C., A continuing legend: the Brookhart-type $\alpha$-diimine nickel and palladium catalysts. Polym. Chem. 2019, 10(19), 2354-2369.

(4) Chen, Z.; Brookhart, M., Exploring Ethylene/Polar Vinyl Monomer Copolymerizations Using Ni and Pd $\alpha$-Diimine Catalysts. Acc. Chem. Res. 2018, $51(8), 1831-1839$

(5) Ittel, S. D.; Johnson, L. K.; Brookhart, M., Late-Metal Catalysts for Ethylene Homo- and Copolymerization. Chem. Rev. 2000, 100 (4), 11691204.

(6) Liu, F.-S.; Hu, H.-B.; Xu, Y.; Guo, L.-H.; Zai, S.-B.; Song, K.-M.; Gao, H.Y.; Zhang, L.; Zhu, F.-M.; Wu, Q., Thermostable $\alpha$-Diimine Nickel(II) Catalyst for Ethylene Polymerization: Effects of the Substituted Backbone Structure on Catalytic Properties and Branching Structure of Polyethylene. Macromolecules 2009, 42 (20), 7789-7796.

(7) Rhinehart, J. L.; Brown, L. A.; Long, B. K., A Robust Ni(II) $\alpha$-Diimine Catalyst for High Temperature Ethylene Polymerization. J. Am. Chem. Soc. 2013, 135 (44), 16316-16319.

(8) Sa, S.; Jeon, M.; Kim, S. Y., Controlling branch distribution of polyethylenes by steric tuning of $\mathrm{Ni} \alpha$-diimine complexes based on phenanthrenequinone. J. Mol. Catal. A: Chem. 2014, 393, 263-271.

(9) Dai, S.; Zhou, S.; Zhang, W.; Chen, C., Systematic Investigations of Ligand Steric Effects on $\alpha$-Diimine Palladium Catalyzed Olefin Polymerization and Copolymerization. Macromolecules 2016, 49 (23), 8855-8862.

(10) Guo, L.; Dai, S.; Sui, X.; Chen, C., Palladium and Nickel Catalyzed Chain Walking Olefin Polymerization and Copolymerization. ACS Catal. 2016, 6(1), 428-441.

(11) Muresan, N.; Lu, C. C.; Ghosh, M.; Peters, J. C.; Abe, M.; Henling, L. M.; Weyhermöller, T.; Bill, E.; Wieghardt, K., Bis( $\alpha$-diimine)iron Complexes: Electronic Structure Determination by Spectroscopy and Broken Symmetry
Density Functional Theoretical Calculations. Inorg. Chem. 2008, 47 (11), 4579-4590.

(12) Kreisel, K. A.; Yap, G. P. A.; Theopold, K. H., Synthesis, Characterization, and Electronic Structure of Diimine Complexes of Chromium. Inorg. Chem. 2008, 47(12), 5293-5303.

(13) Nishiyama, H.; Ikeda, H.; Saito, T.; Kriegel, B.; Tsurugi, H.; Arnold, J.; Mashima, K., Structural and Electronic Noninnocence of $\alpha$-Diimine Ligands on Niobium for Reductive $\mathrm{C}-\mathrm{Cl}$ Bond Activation and Catalytic Radical Addition Reactions. J. Am. Chem. Soc. 2017, 139 (18), 6494-6505.

(14) Mashima, K., Redox-Active $\alpha$-Diimine Complexes of Early Transition Metals: From Bonding to Catalysis. Bull. Chem. Soc. Jpn. 2020, 93 (6), 799820.

(15) Shimizu, M.; Kamei, M.; Fujisawa, T., Stereocontrol in the reduction of 1,2-diimine with an oxazaborolidine catalyst. Highly stereoselective preparation of (R,R)-1,2-diphenylethylenediamine. Tetrahedron Lett. 1995, $36(47), 8607-8610$.

(16) Zhu, X.; Du, H., A Highly Stereoselective Metal-Free Hydrogenation of Diimines for the Synthesis of Cis-Vicinal Diamines. Org. Lett. 2015, 17 (12), 3106-3109.

(17) Hopkinson, M. N.; Richter, C.; Schedler, M.; Glorius, F., An overview of N-heterocyclic carbenes. Nature 2014, 510 (7506), 485-496.

(18) Hintermann, L., Expedient syntheses of the N-heterocyclic carbene precursor imidazolium salts IPr.HCl, IMes. $\mathrm{HCl}$ and IXy.HCl. Beilstein Journal of Organic Chemistry 2007, 3, 22.

(19) Queval, P.; Jahier, C.; Rouen, M.; Artur, I.; Legeay, J.-C.; Falivene, L.; Toupet, L.; Crévisy, C.; Cavallo, L.; Baslé, O.; Mauduit, M., Multicomponent Synthesis of Unsymmetrical Unsaturated N-Heterocyclic Carbene Precursors and Their Related Transition-Metal Complexes. Angew. Chem. Int. Ed. 2013, 52(52), 14103-14107.

(20) Li, S.; Yang, F.; Lv, T.; Lan, J.; Gao, G.; You, J., Synthesis of unsymmetrical imidazolium salts by direct quaternization of $\mathrm{N}$-substituted imidazoles using arylboronic acids. Chem. Commun. 2014, 50 (30), 3941-3943.

(21) Jeon, M.; Kim, S. Y., Ethylene Polymerizations with Unsymmetrical ( $\alpha-$ Diimine)nickel(II) Catalysts. Polym. J. 2008, 40 (5), 409-413.

(22) Benhamou, L.; Chardon, E.; Lavigne, G.; Bellemin-Laponnaz, S.; César, V., Synthetic Routes to N-Heterocyclic Carbene Precursors. Chem. Rev. 2011, $111(4), 2705-2733$.

(23) Rosar, V.; Meduri, A.; Montini, T.; Fornasiero, P.; Zangrando, E.; Milani, B., The contradictory effect of the methoxy-substituent in palladium-catalyzed ethylene/methyl acrylate cooligomerization. Dalton Trans. 2018, 47 (8), 2778-2790

(24) Ellandula, S. K.; Opoku Amoako, C.; Mague, J. T.; Chandrasekaran, P., Crystal structure of unsymmetrical [alpha]-diimine palladium(II) complex cis$[\{\mathrm{ArN}=\mathrm{C}(\mathrm{Me})-(\mathrm{Et}) \mathrm{C}=\mathrm{NAr}\} \mathrm{PdCl} 2] \quad[\mathrm{Ar}=2,6-(\mathrm{iPr}) 2 \mathrm{C} 6 \mathrm{H} 3] . \quad$ Acta Crystallographica Section E2017, 73 (8), 1148-1150.

(25) Kison, C.; Opatz, T., Synthesis of Highly Substituted Unsymmetrical 1,2Diamines, 1,2-Diimines, Imidazolium Salts and Imidazolylidenes by Aldimine Cross-Coupling. Synthesis 2006, 2006(21), 3727-3738.

(26) Wang, J.; Cheng, X.; Liu, Y.; Zhang, J., Multicomponent Synthesis of Unsymmetrical 4,5-Disubstituted Imidazolium Salts as N-Heterocyclic Carbene Precursors: Applications in Palladium-Catalyzed Cross-Coupling Reactions. J. Org. Chem. 2021, 86(9), 6278-6288.

(27) Gilbert, Z. W.; Hue, R. J.; Tonks, I. A., Catalytic formal [2+2+1] synthesis of pyrroles from alkynes and diazenes via $\mathrm{Ti}^{\mathrm{II}} / \mathrm{Ti}^{\mathrm{IV}}$ redox catalysis. Nat. Chem. 2015, $8,63$.

(28) Desnoyer, A. N.; See, X. Y.; Tonks, I. A., Diverse Reactivity of Diazatitanacyclohexenes: Coupling Reactions of $2 \mathrm{H}$-Azirines Mediated by Titanium(II). Organometallics 2018, 37 (23), 4327-4331.

(29) Beaumier, E. P.; Pearce, A. J.; See, X. Y.; Tonks, I. A., Modern applications of low-valent early transition metals in synthesis and catalysis. Nat. Rev. Chem. 2019, 3(1), 15-34.

(30) Pearce, A. J.; Harkins, R. P.; Reiner, B. R.; Wotal, A. C.; Dunscomb, R. J.; Tonks, I. A., Multicomponent Pyrazole Synthesis from Alkynes, Nitriles, and Titanium Imido Complexes via Oxidatively Induced $\mathrm{N}-\mathrm{N}$ Bond Coupling. J. Am. Chem. Soc. 2020, 142 (9), 4390-4399.

(31) Zeng, J.; Tan, Y. J.; Leow, M. L.; Liu, X.-W., Copper(II)/Iron(III) Cocatalyzed Intermolecular Diamination of Alkynes: Facile Synthesis of Imidazopyridines. Org. Lett. 2012, 14 (17), 4386-4389.

(32) Dwivedi, V.; Kumar, R.; Sharma, K.; Sridhar, B.; Reddy, M. S., CopperPromoted Regioselective Intermolecular Diamination of Ynamides: Synthesis of Imidazo[1,2-a]pyridines. ACS Omega 2017, 2 (6), 2770-2777. 
(33) He, C.; Hao, J.; Xu, H.; Mo, Y.; Liu, H.; Han, J.; Lei, A., Heteroaromatic imidazo $[1,2-\mathrm{a}]$ pyridines synthesis from $\mathrm{C}-\mathrm{H} / \mathrm{N}-\mathrm{H}$ oxidative crosscoupling/cyclization. Chem. Commun. 2012, 48 (90), 11073-11075.

(34) Li, J.; Neuville, L., Copper-Catalyzed Oxidative Diamination of Terminal Alkynes by Amidines: Synthesis of 1,2,4-Trisubstituted Imidazoles. Org. Lett. 2013, $15(7), 1752-1755$.

(35) Muñiz, K.; Martínez, C., Development of Intramolecular Vicinal Diamination of Alkenes: From Palladium to Bromine Catalysis. J. Org. Chem. 2013, $78(6), 2168-2174$.

(36) Olson, D. E.; Su, J. Y.; Roberts, D. A.; Du Bois, J., Vicinal Diamination of Alkenes under Rh-Catalysis. J. Am. Chem. Soc. 2014, 136(39), 13506-13509. (37) Zhu, Y.; Cornwall, R. G.; Du, H.; Zhao, B.; Shi, Y., Catalytic Diamination of Olefins via N-N Bond Activation. Acc. Chem. Res. 2014, 47 (12), 3665 3678.

(38) Muñiz, K.; Barreiro, L.; Romero, R. M.; Martínez, C., Catalytic Asymmetric Diamination of Styrenes. J. Am. Chem. Soc. 2017, 139(12), 43544357.

(39) Tao, Z.; Gilbert, B. B.; Denmark, S. E., Catalytic, Enantioselective synDiamination of Alkenes. J. Am. Chem. Soc. 2019, 141 (48), 19161-19170.

(40) Minakata, S.; Miwa, H.; Yamamoto, K.; Hirayama, A.; Okumura, S., Diastereodivergent Intermolecular 1,2-Diamination of Unactivated Alkenes Enabled by Iodine Catalysis. J. Am. Chem. Soc. 2021, 143 (11), 4112-4118. (41) Selby, J. D.; Manley, C. D.; Feliz, M.; Schwarz, A. D.; Clot, E.; Mountford P., New ligand platforms for developing the chemistry of the $\mathrm{Ti}=\mathrm{N}-\mathrm{NR}_{2}$ functional group and the insertion of alkynes into the $\mathrm{N}-\mathrm{N}$ bond of a $\mathrm{Ti}=\mathrm{N}-$ $\mathrm{NPh}_{2}$ ligand. Chem. Commun. 2007, (46), 4937-4939.

(42) Manßen, M.; Schafer, L. L., Titanium catalysis for the synthesis of fine chemicals - development and trends. Chem. Soc. Rev. 2020, 49 (19), $6947-$ 6994.

(43) Basuli, F.; Aneetha, H.; Huffman, J. C.; Mindiola, D. J., A Fluorobenzene Adduct of Ti(IV), and Catalytic Carboamination to Prepare $\alpha, \beta$-Unsaturated Imines and Triaryl-Substituted Quinolines. J. Am. Chem. Soc. 2005, 127(51), 17992-17993.

(44) Basuli, F.; Wicker, B.; Huffman, J. C.; Mindiola, D. J., Understanding the role of an easy-to-prepare aldimine-alkyne carboamination catalyst, $\left[\mathrm{Ti}\left(\mathrm{NMe}_{2}\right)_{3}\left(\mathrm{NHMe}_{2}\right)\right]\left[\mathrm{B}\left(\mathrm{C}_{6} \mathrm{~F}_{5}\right)_{4}\right]$. J. Organomet. Chem. 2011, 696(1), 235243.

(45) Davis-Gilbert, Z. W.; Yao, L. J.; Tonks, I. A., Ti-Catalyzed Multicomponent Oxidative Carboamination of Alkynes with Alkenes and Diazenes. J. Am. Chem. Soc. 2016, 138 (44), 14570-14573.

(46) Cao, C.; Shi, Y.; Odom, A. L., A Titanium-Catalyzed Three-Component Coupling To Generate $\alpha, \beta$-Unsaturated $\beta$-Iminoamines. J. Am. Chem. Soc. 2003, 125 (10), 2880-2881.

(47) Priewisch, B.; Rück-Braun, K., Efficient Preparation of Nitrosoarenes for the Synthesis of Azobenzenes. J. Org. Chem. 2005, 70 (6), 2350-2352.

(48) Dunn, S. C.; Hazari, N.; Cowley, A. R.; Green, J. C.; Mountford, P., Synthesis and Reactions of Group 4 Imido Complexes Supported by Cyclooctatetraene Ligands. Organometallics 2006, 25 (7), 1755-1770.

(49) Blum, S. A.; Bergman, R. G., Nitro and Nitroso Metathesis Reactions with Monomeric Zirconium Imido Complexes. Organometallics 2004, 23 (17), 4003-4005.

(50) Curtin, D. Y.; Grubbs, E. J.; McCarty, C. G., Uncatalyzed syn-anti Isomerization of Imines, Oxime Ethers, and Haloimines. J. Am. Chem. Soc. 1966, 88 (12), 2775-2786.

(51) See, X. Y.; Beaumier, E. P.; Davis-Gilbert, Z. W.; Dunn, P. L.; Larsen, J. A.; Pearce, A. J.; Wheeler, T. A.; Tonks, I. A., Generation of $\mathrm{Ti}^{\mathrm{II}}$ Alkyne Trimerization Catalysts in the Absence of Strong Metal Reductants. Organometallics 2017, 36(7), 1383-1390.

(52) Davis-Gilbert, Z. W.; Kawakita, K.; Blechschmidt, D. R.; Tsurugi, H.; Mashima, K.; Tonks, I. A., In Situ Catalyst Generation and BenchtopCompatible Entry Points for $\mathrm{Ti}^{\mathrm{II}} / \mathrm{Ti}^{\mathrm{IV}}$ Redox Catalytic Reactions. Organometallics 2018, 37(23), 4439-4445.

(53) Seeman, J. I., Effect of conformational change on reactivity in organic chemistry. Evaluations, applications, and extensions of Curtin-Hammett Winstein-Holness kinetics. Chem. Rev. 1983, 83(2), 83-134.

(54) Chiu, H.-C.; See, X. Y.; Tonks, I. A., Dative Directing Group Effects in TiCatalyzed $[2+2+1]$ Pyrrole Synthesis: Chemo- and Regioselective Alkyne Heterocoupling. ACS Catal. 2019, 9 (1), 216-223.

(55) Cheng, Y.; Klein, C. K.; Tonks, I. A., Synthesis of pentasubstituted 2-aryl pyrroles from boryl and stannyl alkynes via one-pot sequential Ti-catalyzed [2 $+2+1$ ] pyrrole synthesis/cross coupling reactions. Chem. Sci. 2020, 11 (37), 10236-10242.
(56) Kawakita, K.; Parker, B. F.; Kakiuchi, Y.; Tsurugi, H.; Mashima, K.; Arnold, J.; Tonks, I. A., Reactivity of terminal imido complexes of group 4-6 metals: Stoichiometric and catalytic reactions involving cycloaddition with unsaturated organic molecules. Coord. Chem. Rev. 2020, 407, 213118.

(57) Schofield, A. D.; Nova, A.; Selby, J. D.; Schwarz, A. D.; Clot, E.; Mountford, P., Reaction Site Diversity in the Reactions of Titanium Hydrazides with Organic Nitriles, Isonitriles and Isocyanates: $\mathrm{Ti}=\mathrm{N}_{\alpha}$ Cycloaddition, $\mathrm{Ti}=\mathrm{N}_{\alpha}$ Insertion and $\mathrm{N}_{\alpha}-\mathrm{N}_{\beta}$ Bond Cleavage. Chem-Eur. J2011, $17(1), 265-285$.

(58) Manßen, M.; de Graaff, S.; Meyer, M.-F.; Schmidtmann, M.; Beckhaus, R., Direct Access to Titanocene Imides via $\operatorname{Bis}\left(\eta^{5}: \eta^{1}\right.$-penta-fulvene)titanium Complexes and Primary Amines. Organometallics 2018, 37(23), 4506-4514.

(59) Barluenga, J.; Pozo, C. d.; Olano, B., Reactions of N-Unsubstituted 4 Amino-1-azadienes Towards Electrophiles. Synthesis 1996, 1996 (01), 133 140 .

(60) Carosso, S.; Miller, M. J., Nitroso Diels-Alder (NDA) reaction as an efficient tool for the functionalization of diene-containing natural products. Org. Biomol. Chem. 2014, 12 (38), 7445-7468.

(61) Maji, B.; Yamamoto, H., Catalytic Enantioselective Nitroso Diels-Alder Reaction. J. Am. Chem. Soc. 2015, 137(50), 15957-15963.

(62) Bleeke, J. R.; Hinkle, P. V.; Rath, N. P., Synthesis, Structure, Spectroscopy, and Reactivity of a Metallathiabenzene. Organometallics 2001, 20(10), 1939 1951.

(63) Holland, R. L.; O’Connor, J. M., Nitroso Compounds Serve as Precursors to Late-Metal $\eta^{2}(\mathrm{~N}, \mathrm{O})$-Hydroxylamido Complexes. Organometallics 2009, 28 (2), 394-396.

(64) Basuli, F.; Huffman, J. C.; Mindiola, D. J., Reactivity at the $\beta$-Diketiminate Ligand Nacnac- on Titanium(IV) (Nacnac- = $\left.[\mathrm{Ar}] \mathrm{NC}\left(\mathrm{CH}_{3}\right) \mathrm{CHC}\left(\mathrm{CH}_{3}\right) \mathrm{N}[\mathrm{Ar}], \mathrm{Ar}=2,6-\left[\mathrm{CH}\left(\mathrm{CH}_{3}\right)_{2}\right]_{2} \mathrm{C}_{6} \mathrm{H}_{3}\right)$. Diiminealkoxo and Bis-anilido Ligands Stemming from the Nacnac- Skeleton. Inorg. Chem. 2003, 42 (24), 8003-8010.

(65) Basuli, F.; Bailey, B. C.; Watson, L. A.; Tomaszewski, J.; Huffman, J. C.; Mindiola, D. J., Four-Coordinate Titanium Alkylidene Complexes: Synthesis, Reactivity, and Kinetic Studies Involving the Terminal Neopentylidene Functionality. Organometallics 2005, 24(8), 1886-1906.

(66) Avarvari, N.; Le Floch, P.; Ricard, L.; Mathey, F., 1,3,2Diazaphosphinines and -Diazaarsinines as Precursors for Polyfunctional Phosphinines and Arsinines. Organometallics 1997, 16 (19), 4089-4098.

(67) A similar coordinated diimine intermediate has been made through reductive nitrile coupling followed by adventitious $\mathrm{H}$ abstraction: Becker, L.; Strehler, F.; Korb, M.; Arndt, P.; Spannenberg, A.; Baumann, W.; Lang, H.; Rosenthal, U., Unusual Nitrile-Nitrile and Nitrile-Alkyne Coupling of Fc$\mathrm{C} \equiv \mathrm{N}$ and $\mathrm{Fc}-\mathrm{C} \equiv \mathrm{C}-\mathrm{C} \equiv \mathrm{N}$. Chem-Eur. J2014, 20(11), 3061-3068.

(68) Kortman, G. D.; Orr, M. J.; Hull, K. L., Synthesis and Reactivity of Dioxazirconacyclohexenes: Development of a Zirconium-Oxo-Mediated Alkyne-Aldehyde Coupling Reaction. Organometallics 2015, 34 (6), 1013 1016.

(69) Nguyen, T. T.; Kortman, G. D.; Hull, K. L., Synthesis, Cycloaddition, and Cycloreversion Reactions of Mononuclear Titanocene-oxo Complexes. Organometallics 2016, 35 (11), 1713-1725.

(70) Doxsee, K. M.; Mouser, J. K. M., Titanium-mediated synthesis of conjugated dienes. Tetrahedron Lett. 1991, 32 (14), 1687-1690.

(71) Polse, J. L.; Andersen, R. A.; Bergman, R. G., Cycloaddition and Cycloreversion Reactions of a Monomeric Ti(IV) Oxo Complex with Terminal and Internal Alkynes. A Reversible Oxametallacyclobutene/Hydroxoacetylide Interconversion. J. Am. Chem. Soc. 1995, 117(19), 5393-5394.

(72) Ruck, R. T.; Zuckerman, R. L.; Krska, S. W.; Bergman, R. G. Carboamination: Additions of Imine $\mathrm{C}=\mathrm{N}$ Bonds Across Alkynes Catalyzed by Imidozirconium Complexes. Angew. Chem. Int. Ed. 2004, 43 (40), 5372-5374. (73) Hanna, T. A.; Baranger, A. M.; Walsh, P. J.; Bergman, R. G., Formation of .alpha.,.beta.-Unsaturated Imines and Successful Trapping of Oxozirconocene in a $[4+2]$ Azaoxametallacyclohexene Retrocycloaddition. J. Am. Chem. Soc 1995, 117(11), 3292-3293.

(74) Doxsee, K. M.; Juliette, J. J. J.; Weakley, T. J. R.; Zientara, K., Nitrosoarene and nitrosoalkane insertion reactions of titanacyclobutenes. Inorg. Chim. Acta 1994, 222 (1), 305-315.

(75) Nakamoto, M.; Tilley, T. D., Reactions of Zirconacyclopentadienes with Nitrosobenzene. Characterization of Zirconacycle Intermediates and Formation of N-Phenylpyrroles. Organometallics 2001, 20 (26), 5515-5517. 


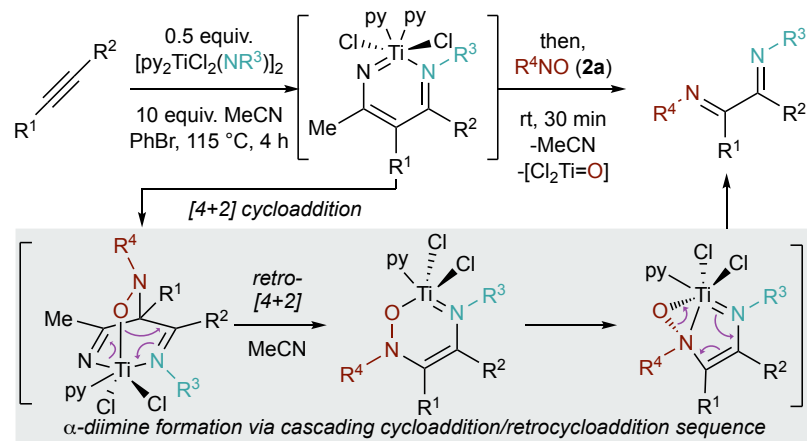

